\title{
Der Künstler und seine Chirurgen
}

\author{
Erhard Taverna
}

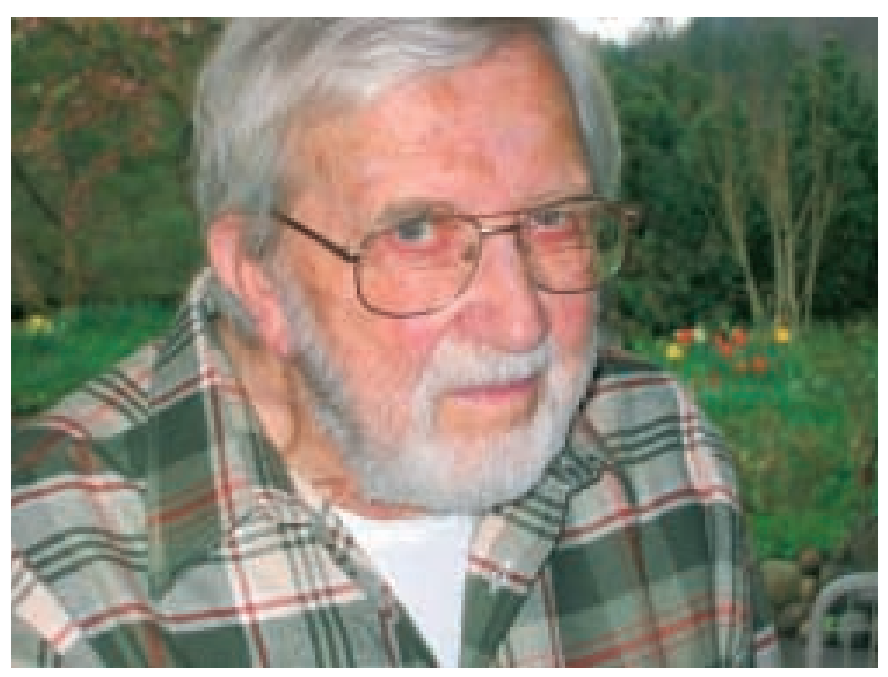

Schon früh am Morgen mussten die Bewerber im Operationssaal antreten und einen Eingriff zeichnerisch begleiten. Dann verglich Prof. Hugo Krayenbühl die Resultate und wählte Hans Peter Weber zum wissenschaftlichen Zeichner der neurochirurgischen Universitätsklinik in Zürich. Während Stunden, zumeist stehend, hat dieser mit Bleistift skizziert, mit Buchstaben die Farbnuancen bezeichnet und danach seine Blätter im Spitalatelier fertig ausgearbeitet. Weit über 4000 Operationen hat er von 1947 bis 1979 protokolliert und mit weiteren Zeichnungen und schematischen Bildern wissenschaftliche Publikationen, Lehrbücher und Vorträge illustriert. Viele Ausgaben der «Documenta Geigy» aus den 50er und 60er Jahren tragen die Handschrift des Künstlers.

Hans Peter Weber* ist am 27. April 1914 in Bern geboren. Sein Vater unterrichtete Latein, Englisch und Religion am Freien Gymnasium. Erst siebenjährig malte er aus eigenem Antrieb originelle Blumenaquarelle. Das Latein war ihm für die anatomischen Bezeichnungen nützlich, das Interesse am Organischen weckte in ihm früh sein Onkel, der als Tierarzt in Laupen unterwegs war. Bei der Firma Kümmerly \& Frey machte er seine Grafikerlehre. Dem Abschluss folgten bis zum Kriegsende wirtschaftlich schwierige Zeiten, in denen er um jede Gelegenheitsarbeit froh sein musste. Er war als Retoucheur bei der Firma Hallwag in Bern, in der Ecole graphique PaulColin in Paris und an der Kunstgewerbeschule in
Zürich. Er zeichnete die begehrten Schokoladebeilagebildchen von Nestlé Peter Cailler Kohler, Briefmarkenentwürfe für die Post und zahlreiche Abbildungen für das «Schweizer Lexikon». Bis zum Aktivdienst sicherte ihm die Landesausstellung für eine Weile ein Einkommen als Schriftenmaler.

Als medizinischer Illustrator blieb er bis zur Pensionierung der Neurochirurgie verbunden, wobei er nebenher noch in der Kunstgewerbeschule Kurse für Naturstudien anbot und später als Fachlehrer für wissenschaftliches Zeichnen in Chirurgie und Medizin unterrichtete. Im Rückblick lobt er die damalige familiäre Atmosphäre, die freundschaftliche Zusammenarbeit mit seinen Chirurgen Krayenbühl, Yasargil, Yonekawa, Clodius und Brunner und die vielen Kontakte mit Patienten und Mitarbeitern des Spitals. Einengende Vorschriften gab es für ihn keine. Er war auf Visiten und Ausflügen dabei, hatte Zugang zu den Krankengeschichten, beriet Assistenten und Studenten und feierte mit an Spitalfesten und akademischen Ehrungen. Mit in der Tasche, wie in allen Lebensjahren, war immer auch sein Skizzenheft.

Etwas vom Schönsten sei seine Zusammenarbeit mit Susan R. Bach aus London, der beratenden Psychologin an der Neurochirurgie des USZ, gewesen. Als Resultat eines jahrelangen Forschungsprojektes veröffentlichte sie 1961 ihre ersten, viel beachteten Interpretationen: «Spontanes Malen und Zeichnen im neurochirurgischen Bereich». Sie beschreibt darin Hans Peter Webers Wandbild von der Arche Noah in der Kinderabteilung und schildert seinen feinfühligen Umgang mit den kleinen Patienten: «Er stellt sich vor, sagt, dass er kein Arzt sei, aber Kinder lieb habe und selber gern male, und dass er alles sammle, was sie zum Zeitvertreib zeichnen, kleben, aus Streichholzschachteln basteln usw. Er setzt sich zu dem Neuangekommenen, legt ihm ganz nebenbei ein Brettchen mit Papier und Zeichenstiften aufs Bett, fragt nach seinem $\mathrm{Zu}$ hause, nach seinen Beschwerden und versichert ihm, dass die Klinik alles tun wird, ihm zu helfen, bald wieder gesund zu werden.» Über viele Jahre fruchtbarer Zusammenarbeit entstand mit seiner Hilfe eine systematisch katalogisierte Sammlung von Zeichnungen schwerkranker Kinderpatienten. 


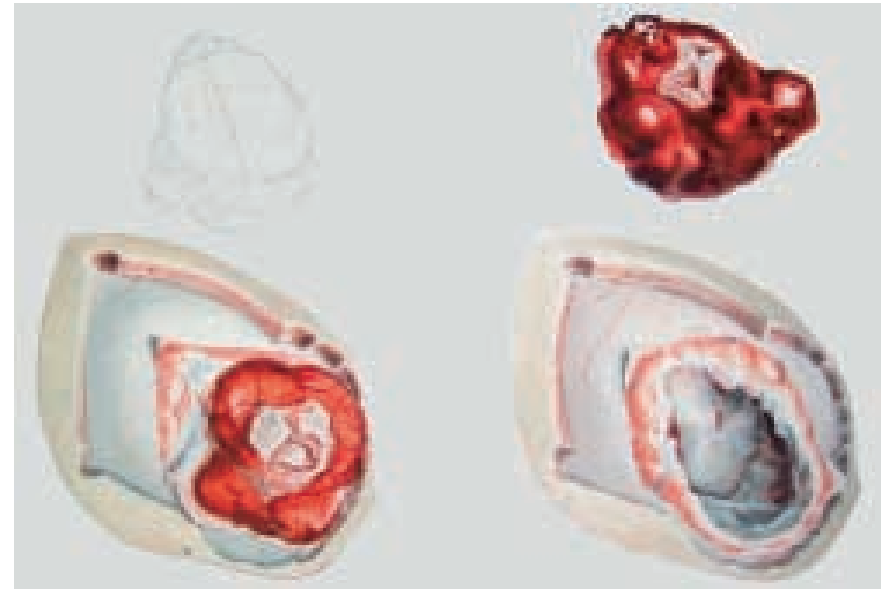

Nach der Pensionierung lehrte Hans Peter Weber über viele Jahre an der Volkshochschule in Zürich und in zahlreichen Privatkursen und Malreisen. Sein schönes Haus, das er, von seiner zweiten Ehefrau Lis liebevoll umsorgt, in Zumi- kon bewohnt, hängt voller Acryl- und Aquarellbilder, zu denen auch Künstlerfreunde und Schüler beigetragen haben. Ein exakter Beobachter und Sammler ist er geblieben. Er hat die weltweit grösste und graphisch interessanteste Sammlung von Orangenverpackungspapieren, mangels Interesse und Geld in der Schweiz, nach Deutschland verkauft, wo sie schon mehrmals ausgestellt wurde. Er hat aus eingeschmolzenem Flaschenzinn wunderbare Aktskulpturen modelliert oder aus den Abfallscherben von Kirchenfenstern ein perfektes Puzzle von Eva und Adam geschaffen. Nach 32 Jahren wissenschaftlich-klinischer Illustrationen und einem langen tätigen Leben malt Hanspeter Weber seine inneren Bilder als grossflächige, bunte Abstraktionen. Gesunder und immer wacher Beobachter, skizziert er seinen vielseitigen Alltag als aktiver Teilnehmer in präzis-rhythmischen Strichfolgen, die, als intime Tagebücher vieler Jahrzehnte, inzwischen ganze Buchregale füllen.

\section{Ärzte stellen Bilder und Plastiken aus}

\section{Kunstausstellung der Schweizer Ärzte}

\section{Salon des Médecins Suisses}
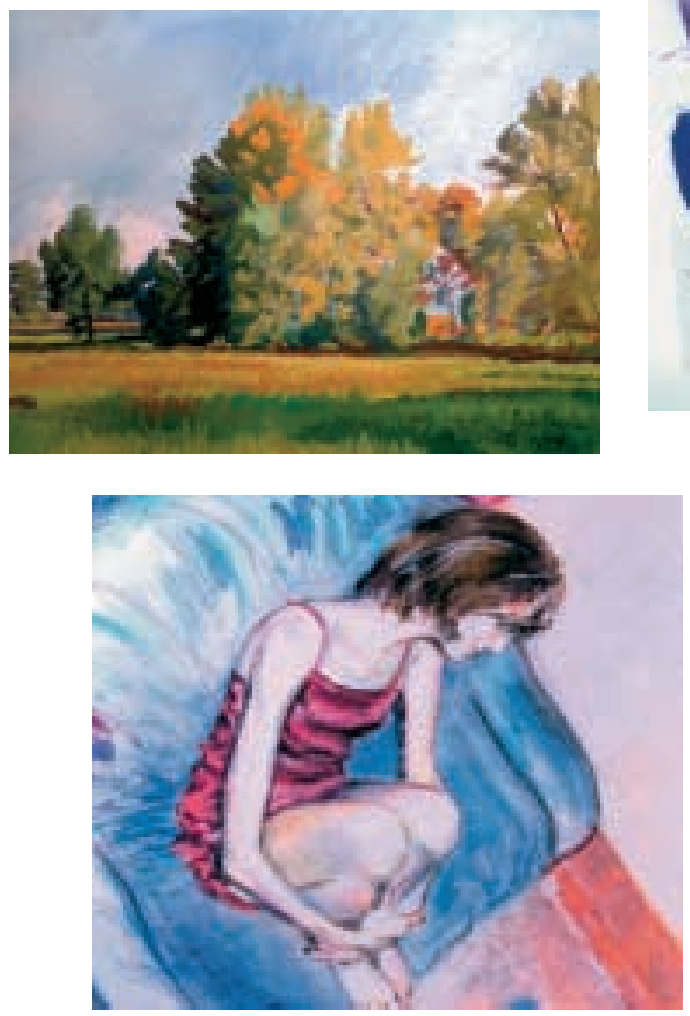
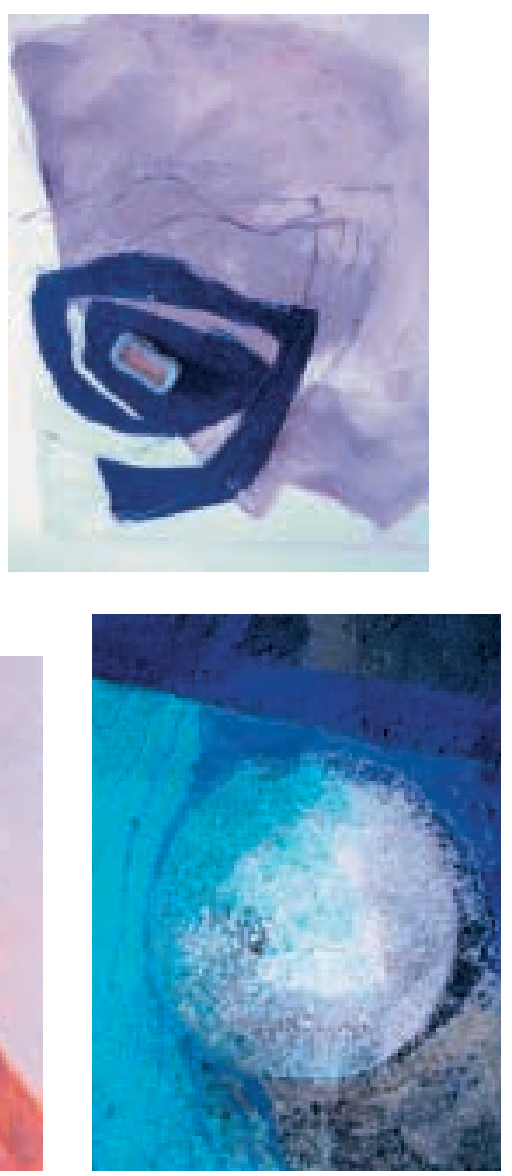

Einladung zur Sommerausstellung vom 21. Mai bis 9. Juli 2005

Galerie zur Hammermühle, Schützenstrasse 77, 6438 Schwyz lbach, www.hanni-mirer.ch

Öffnungszeiten Galerie und Gewürzboutique: Montag-Freitag 8.00-12.00 Uhr und 14.00-18.30 Uhr Samstag 9.00-12.00 Uhr und 14.00-16.00 Uhr Der Erlös der Ausstellung geht zu Gunsten der Stiftung Welt ohne Minen.

Es freuen sich auf Ihren Besuch

Hanni Mirer Stöckli und Klaus Stöckli-Mirer 